Current Research in Dentistry 3 (1): 1-6, 2012

ISSN 1949-0119

(C) 2012 Science Publications

\title{
Frictional Properties of Self-Ligating Brackets and Low-Friction Ligatures
}

\author{
Maria Francesca Sfondrini, Danilo Fraticelli, \\ Federico Rosti, Andrea Scribante and Paola Gandini \\ Department of Orthodontics, Faculty of Dentistry, University of Pavia, Italy
}

\begin{abstract}
Problem statement: To evaluate the frictional forces generated by five different orthodontic brackets when used in combination with stainless steel and NiTi archwires in dry conditions at physiological temperature. Approach: Five different types of maxillary canine brackets (Damon 3 MX, Step, Quick, Sprint, Mini Mono) with a slot size 0.022 inch were coupled with 0.016 " and 0.019 " $\times 0.025$ " stainless steel and with 0.016 " and 0.018 " $\times 0.025$ " NiTi archwires. Step, Sprint and Mini Mono were used both with traditional ligatures and with Slide ligatures. A total of 320 archwires and brackets were used; ten tests were carried out for each group of bracket-wire combination at physiological temperature and in dry state. Frictional forces were measured by Instron Universal Testing Machine. The statistical significance level was established at $\mathrm{P}<0.05$. Results: Damon 3 MX and Step brackets with Slide ligatures produced statistically lower friction than Quick and conventional brackets with elastomeric ligature. Frictional force increased proportionally to the wire size; NiTi archwires presented higher frictional resistance than stainless steel archwires. Slide ligatures showed lower fictional values in comparison with elastic ligatures. Conclusion: Stainless steel brackets with new Slide ligature show frictional forces similar to self-ligating brackets with passive clip.
\end{abstract}

Key words: Self-ligating brackets, slide ligatures, elastomeric ligatures, brackets, frictional resistance, friction, force, bracket-wire combinations, tests machine, instron, orthodontic, appliance, dentistry

\section{INTRODUCTION}

In orthodontic practice, during closure of extraction spaces, tooth movement with sliding is a very common procedure (Cacciafesta et al., 2003). Whenever sliding occurs, friction should be encountered. Friction is defined as "the force tangential to common boundary of two bodies in contact that resist the motion of one relative to the other. The amount of friction is proportional to the force with which the two surfaces are pressed together and dependent on the nature of the surfaces in contact (Articolo et al., 2000). The application of force has to overcome the friction to allow tooth movement. The dissipation of the orthodontic force as resistance to sliding may vary between 12 and $60 \%$ or it may lead a stop in orthodontic movement (Chimenti et al., 2008).

Friction may be divided into static friction, which is the force required to initiate tooth movement and is always stronger than the kinetic friction, which keeps body in motion (Chimenti et al., 2008). Because tooth movement along an archwire is not continuous but occurs in a series of very short steps, static friction is considered to have more importance because it needs to be overcome each time the tooth moves a little (Cacciafesta et al., 2003).

Resistance to Sliding (RS) of an archwire-bracket couple is the combined effect of 3 components: Classical Friction (FR), elastic Binding (BI) and physical Notching (NO) (Articolo et al., 2000). FR depends on ligation force and bracket-archwire material (Thorstenson and Kusy, 2003). When the archwire just contacts both edges of the slot wall as the bracket is angulated relative to the archwire, the BI component begins to contribute the RS. The angle $(\theta)$ at which the archwire first contacts the edges of the slot walls is called the critical contact angle for binding (Kusy and Whitley, 2001) At greater values

Corresponding Author: Andrea Scribante, Department of Orthodontics, Faculty of Dentistry, University of Pavia, Italy 
of $\theta$, the bracket may physically deform the archwire, thus adding NO component to the components of RS (Articolo et al., 2000).

Many studies have evaluated the factors that affect frictional forces released during sliding mechanics: bracket and wire materials, bracket width, slot size, wire section, wire size, second order angulation and torque at the wire bracket interface, surface conditions of the archwires and the bracket slots, type and force of ligation, interbracket distance, saliva and influence of oral functions (Cacciafesta et al., 2003; Hain et al., 2003; Henao and Kusy, 2004; Thorstenson and Kusy, 2003; Wichelhaus et al., 2005).

Friction is determined mostly by the nature of ligation (Griffiths et al., 2005). Self-ligating brackets were introduced in early 1930s in form of Russel attachment, which was intended to reduce ligation times and to improve operator efficiency (Berger, 2000; Northrup et al., 2007; Sfondrini et al., 2011). From patient's perspective self-ligating brackets are generally smoother, more comfortable and easier to clean due to absence of wire ligatures (Berger, 2000). Besides these, another benefit of self-ligating brackets has been their low frictional resistance (Henao and Kusy, 2004). Two types of self-ligating brackets have been developed; those that have a spring clip which presses against the archwire and those self-ligating mechanism that do not press against the arch wire.

In self-ligating brackets the movable spring clip converted the slot into a tube (Sfondrini et al., 2010); several previous studies demonstrated a significant decrease in friction for self-ligating brackets, compared to conventional stainless steel brackets. Such a reduction in friction can help shorten chairtime and treatment (Henao and Kusy, 2004).

Newly introduced Slide low friction ligatures have been developed to transform common stainless steel brackets in a sort of self-ligating bracket, where the fourth wall of the slot is the poliuretane surface of the ligature.

The purpose of this in vitro study was to evaluate the frictional forces generated by 3 types brackets (conventional stainless steel, interactive self-ligating, passive self-ligating) in combination with 2 different alloys (stainless steel and NiTi archwires) of 3 different section (0.016", $0.018 " \times 0.025 "$ and $0.019 " \times 0.025 ")$ in combination with conventional and Slide ligatures.

\section{MATERIALS AND METHODS}

Five different types of preadjusted maxillary canine brackets were tested: conventional stainless steel (Step, Leone S.p.a. Firenze, Italy; Mini Mono, Forestadent, Pforzheim, Germany; Sprint, Forestadent, Pforzheim, Germany) and stainless steel self-ligating brackets (Damon 3 MX, Ormco, Glendora, Ca; Quick, Forestadent, Pforzheim, Germany). Two types of archwire alloys were tested: stainless steel (Forestadent, Pforzheim, Germany) and NiTi (Titanol-Martensitic, Forestadent and Pforzheim, Germany).

All the brackets were 0022 " slot and were tested with 3 wire section: 0016", 0.018 " $\times 0.025$ " and 0.019 " $\times 0.025$ ". Conventional stainless steel brackets were used either with traditional ligatures in modules (Forestadent, Pforzheim, Germany) or with Slide ligatures (Leone S.p.a. Firenze, Italy). A total of 320 samples were studied (Table1, 2); after each sample bracket, wire and ligature were changed to eliminate the effect of wear. A Universal Testing Machine Instron 4444 (Instron Industrial Products, Grove City, Pennsylvania, USA) was used to measure and record the frictional forces released. Each bracket was bonded with a laser weld to a stainless steel screw and then it was positioned in the testing apparatus. Each wire was ligated to the bracket using elastomeric ligatures, or closing the clip of self-ligating brackets. The speed of the machine was being $2.5 \mathrm{~mm} / \mathrm{min}$ for a total of 2 min per experiment. All the samples were performed in dry conditions at physiological temperature. The system of acquisition measured the force values (Newtons) needed to move the bracket along the wire and the values were recorded by a computer. The static friction was calculated at the initial peak of movement. The dynamic friction was calculated as average of 10 acquisitions made at a distance of 5 seconds each, after the peak (Cacciafesta et al., 2003). Statistical analysis was performed with Stata 7 software (Stata, College Station,Tex); a Kruskal-Wallis test was used to study the effect of bracket type, wire alloy, section and ligature on friction. A Mann-Whitney U test was used for the post hoc test and the Bonferroni adjustment was applied. Then, a generalized linear regression model was fitted to check the combined effect of the 4 variables (bracket, alloy, section and ligature) and their interactions. The level of significance was set for $\mathrm{P}<0.05$. 
Current Research in Dentistry 3 (1): 1-6, 2012

Table 1: Static Friction values $(\mathrm{N})$ of the different groups tested

\begin{tabular}{|c|c|c|c|c|c|c|c|}
\hline Bracket-wire combination & Ligature & $\mathrm{n}$ & Mean & SD & Min & Mdn & Max \\
\hline Damon NiTi 016 & Self Ligating & 10 & 0.720 & 0.177 & 0.413 & 0.706 & 1.044 \\
\hline Damon NiTi $018 \times 025$ & Self Ligating & 10 & 0.987 & 0.304 & 0.601 & 0.976 & 1.485 \\
\hline Damon Steel 016 & Self Ligating & 10 & 0.536 & 0.131 & 0.384 & 0.505 & 0.781 \\
\hline Damon Steel $019 \times 025$ & Self Ligating & 10 & 1.098 & 0.243 & 0.902 & 0.965 & 1.587 \\
\hline Step NiTi 016 & Conventional elastomeric & 10 & 1.162 & 0.245 & 0.811 & 1.094 & 1.640 \\
\hline Step NiTi $018 \times 025$ & Conventional elastomeric & 10 & 1.496 & 0.240 & 1.122 & 1.438 & 1.903 \\
\hline Step Steel 016 & Conventional elastomeric & 10 & 1.194 & 0.166 & 0.958 & 1.184 & 1.442 \\
\hline Step Steel $019 \times 025$ & Conventional elastomeric & 10 & 1.369 & 0.201 & 1.036 & 1.379 & 1.664 \\
\hline Step + Slide NiTi 016 & Experimental elastomeric & 10 & 0.584 & 0.104 & 0.446 & 0.608 & 0.762 \\
\hline Step + Slide NiTi $018 \times 025$ & Experimental elastomeric & 10 & 0.867 & 0.131 & 0.620 & 0.875 & 1.090 \\
\hline Step + Slide Steel 016 & Experimental elastomeric & 10 & 0.461 & 0.114 & 0.258 & 0.442 & 0.623 \\
\hline Step + Slide Steel $019 \times 025$ & Experimental elastomeric & 10 & 0.747 & 0.194 & 0.478 & 0.772 & 0.985 \\
\hline Quick NiTi 016 & Self Ligating & 10 & 1.156 & 0.218 & 0.749 & 1.195 & 1.511 \\
\hline Quick NiTi $018 \times 025$ & Self Ligating & 10 & 1.582 & 0.273 & 1.160 & 1.615 & 1.885 \\
\hline Quick Steel 016 & Self Ligating & 10 & 0.850 & 0.150 & 0.593 & 0.862 & 1.066 \\
\hline Quick Steel 019×025 & Self Ligating & 10 & 2.190 & 0.572 & 1.136 & 2.338 & 2.892 \\
\hline Mini Mono NiTi 016 & Conventional elastomeric & 10 & 1.269 & 0.195 & 0.891 & 1.270 & 1.498 \\
\hline Mini Mono NiTi $018 \times 025$ & Conventional elastomeric & 10 & 1.447 & 0.232 & 1.063 & 1.464 & 1.815 \\
\hline Mini Mono Steel 016 & Conventional elastomeric & 10 & 1.255 & 0.189 & 0.956 & 1.225 & 1.570 \\
\hline Mini Mono Steel $019 \times 025$ & Conventional elastomeric & 10 & 1.179 & 0.235 & 0.851 & 1.173 & 1.525 \\
\hline Mini Mono + Slide NiTi 016 & Experimental elastomeric & 10 & 0.683 & 0.173 & 0.510 & 0.620 & 1.095 \\
\hline Mini Mono + Slide NiTi $018 \times 025$ & Experimental elastomeric & 10 & 0.926 & 0.207 & 0.572 & 0.979 & 1.173 \\
\hline Mini Mono + Slide Steel 016 & Experimental elastomeric & 10 & 0.411 & 0.103 & 0.306 & 0.396 & 0.666 \\
\hline Mini Mono + Slide Steel $019 \times 025$ & Experimental elastomeric & 10 & 0.695 & 0.148 & 0.440 & 0.682 & 0.966 \\
\hline Sprint NiTi 016 & Conventional elastomeric & 10 & 1.287 & 0.306 & 0.873 & 1.200 & 1.807 \\
\hline Sprint NiTi $018 \times 025$ & Conventional elastomeric & 10 & 1.058 & 0.139 & 0.784 & 1.054 & 1.329 \\
\hline Sprint Steel 016 & Conventional elastomeric & 10 & 0.970 & 0.152 & 0.746 & 0.968 & 1.195 \\
\hline Sprint Steel $019 \times 025$ & Conventional elastomeric & 10 & 1.058 & 0.134 & 0.881 & 1.031 & 1.340 \\
\hline Sprint + Slide NiTi 016 & Experimental elastomeric & 10 & 0.610 & 0.134 & 0.427 & 0.575 & 0.861 \\
\hline Sprint + Slide NiTi $018 \times 025$ & Experimental elastomeric & 10 & 0.584 & 0.174 & 0.274 & 0.605 & 0.856 \\
\hline Sprint + Slide Steel 016 & Experimental elastomeric & 10 & 0.403 & 0.093 & 0.236 & 0.405 & 0.572 \\
\hline Sprint + Slide Steel $019 \times 025$ & Experimental elastomeric & 10 & 0.557 & 0.122 & 0.320 & 0.570 & 0.682 \\
\hline
\end{tabular}

Table 2: Cinetic Friction values $(\mathrm{N})$ of the different groups tested

\begin{tabular}{|c|c|c|c|c|c|c|c|}
\hline Bracket-wire combination & Ligature & $\mathrm{n}$ & Mean & SD & Min & Mdn & Max \\
\hline Damon NiTi 016 & Self Ligating & 10 & 0.842 & 0.234 & 0.370 & 0.871 & 1.166 \\
\hline Damon NiTi $018 \times 025$ & Self Ligating & 10 & 1.039 & 0.321 & 0.666 & 1.011 & 1.611 \\
\hline Damon Steel 016 & Self Ligating & 10 & 0.486 & 0.109 & 0.328 & 0.480 & 0.670 \\
\hline Damon Steel $019 \times 025$ & Self Ligating & 10 & 1.138 & 0.212 & 0.814 & 1.095 & 1.466 \\
\hline Step NiTi 016 & Conventional elastomeric & 10 & 1.292 & 0.269 & 0.937 & 1.295 & 1.861 \\
\hline Step NiTi $018 \times 025$ & Conventional elastomeric & 10 & 1.682 & 0.277 & 1.256 & 1.656 & 2.010 \\
\hline Step Steel 016 & Conventional elastomeric & 10 & 1.300 & 0.179 & 1.033 & 1.313 & 1.640 \\
\hline Step Steel $019 \times 025$ & Conventional elastomeric & 10 & 1.428 & 0.222 & 1.047 & 1.379 & 1.806 \\
\hline Step + Slide NiTi 016 & Experimental elastomeric & 10 & 0.761 & 0.161 & 0.546 & 0.761 & 0.997 \\
\hline Step + Slide NiTi $018 \times 025$ & Experimental elastomeric & 10 & 0.880 & 0.120 & 0.689 & 0.896 & 1.073 \\
\hline Step + Slide Steel 016 & Experimental elastomeric & 10 & 0.509 & 0.092 & 0.317 & 0.486 & 0.618 \\
\hline Step + Slide Steel $019 \times 025$ & Experimental elastomeric & 10 & 0.833 & 0.230 & 0.540 & 0.837 & 1.194 \\
\hline Quick NiTi 016 & Self Ligating & 10 & 1.372 & 0.250 & 1.033 & 1.325 & 1.745 \\
\hline Quick NiTi $018 \times 025$ & Self Ligating & 10 & 1.809 & 0.300 & 1.178 & 1.876 & 2.103 \\
\hline Quick Steel 016 & Self Ligating & 10 & 0.821 & 0.141 & 0.532 & 0.856 & 1.023 \\
\hline Quick Steel 019×025 & Self Ligating & 10 & 2.087 & 0.407 & 1.379 & 2.071 & 2.845 \\
\hline Mini Mono NiTi 016 & Conventional elastomeric & 10 & 1.487 & 0.269 & 1.033 & 1.508 & 1.947 \\
\hline Mini Mono NiTi $018 \times 025$ & Conventional elastomeric & 10 & 1.700 & 0.247 & 1.206 & 1.720 & 2.153 \\
\hline Mini Mono Steel 016 & Conventional elastomeric & 10 & 1.369 & 0.149 & 1.200 & 1.315 & 1.648 \\
\hline Mini Mono Steel $019 \times 025$ & Conventional elastomeric & 10 & 1.324 & 0.242 & 0.951 & 1.329 & 1.686 \\
\hline Mini Mono + Slide NiTi 016 & Experimental elastomeric & 10 & 0.925 & 0.137 & 0.721 & 0.933 & 1.139 \\
\hline Mini Mono + Slide NiTi $018 \times 025$ & Experimental elastomeric & 10 & 1.112 & 0.310 & 0.718 & 1.215 & 1.535 \\
\hline Mini Mono + Slide Steel 016 & Experimental elastomeric & 10 & 0.419 & 0.113 & 0.290 & 0.417 & 0.688 \\
\hline Mini Mono + Slide Steel $019 \times 025$ & Experimental elastomeric & 10 & 0.784 & 0.142 & 0.518 & 0.804 & 0.998 \\
\hline Sprint NiTi 016 & Conventional elastomeric & 10 & 1.463 & 0.282 & 0.980 & 1.412 & 2.059 \\
\hline Sprint NiTi $018 \times 025$ & Conventional elastomeric & 10 & 1.221 & 0.194 & 0.901 & 1.233 & 1.652 \\
\hline Sprint Steel 016 & Conventional elastomeric & 10 & 1.070 & 0.175 & 0.740 & 1.114 & 1.268 \\
\hline Sprint Steel $019 \times 025$ & Conventional elastomeric & 10 & 1.267 & 0.177 & 1.049 & 1.228 & 1.626 \\
\hline Sprint + Slide NiTi 016 & Experimental elastomeric & 10 & 0.801 & 0.194 & 0.609 & 0.726 & 1.097 \\
\hline Sprint + Slide NiTi $018 \times 025$ & Experimental elastomeric & 10 & 0.735 & 0.217 & 0.360 & 0.727 & 1.075 \\
\hline Sprint + Slide Steel 016 & Experimental elastomeric & 10 & 0.428 & 0.105 & 0.245 & 0.443 & 0.541 \\
\hline Sprint + Slide Steel $019 \times 025$ & Experimental elastomeric & 10 & 0.639 & 0.105 & 0.421 & 0.675 & 0.751 \\
\hline
\end{tabular}




\section{RESULTS}

Four variables are studied in this study: Bracket type, wire alloy and section, ligature.

Effect of bracket material: As reported in Table 3, the Kruskal-Wallis test showed a significant bracket effect $(\mathrm{P}=0.0001)$. Post hoc pairwise comparisons showed that Damon 3 MX brackets produced significant lower friction than conventional brackets with elastomeric conventional ligatures and selfligating Quick for static and kinetic friction. No statistical differences were found between Damon 3 Mx and stainless steel brackets with Slide ligature for static and kinetic friction and among conventional brackets with either Slide or traditional ligatures.

Table 3: Scheffé post hoc test for the effect of bracket

\begin{tabular}{lrr}
\hline & Static friction & \multicolumn{2}{c}{ Kinetic friction } \\
Scheffé post hoc & : P value & \multicolumn{1}{c}{ P value } \\
\hline Damon/Step & $<0.0001$ & $<0.0001$ \\
Damon/Step + Slide & 0.0166 & 0.0799 \\
Damon/Mini Mono & $<0.0001$ & $<0.0001$ \\
Damon/Mini Mono + Slide & 0.0282 & 0.3457 \\
Damon/Quick & $<0.0001$ & $<0.0001$ \\
Damon/Sprint & $<0.0001$ & $<0.0001$ \\
Damon/Sprint + Slide & $<0.0001$ & 0.0028 \\
Step/Step + Slide & $<0.0001$ & $<0.0001$ \\
Step/Mini Mono & 0.8738 & 0.3812 \\
Step/Mini Mono + Slide & $<0.0001$ & $<0.0001$ \\
Step/Quick & 0.8211 & 0.4529 \\
Step/Sprint & 0.0001 & 0.0041 \\
Step/Sprint + Slide & $<0.0001$ & $<0.0001$ \\
Step + Slide/Mini Mono & $<0.0001$ & $<0.0001$ \\
Step + Slide/Mini Mono + Slide & 0.8512 & 0.4529 \\
Step + Slide/Quick & $<0.0001$ & $<0.0001$ \\
Step + Slide/Sprint & $<0.0001$ & $<0.0001$ \\
Step + Slide/Sprint + Slide & 0.0090 & 0.0799 \\
Mini Mono Mini Mono + Slide & $<0.0001$ & $<0.0001$ \\
Mini Mono/Quick & 0.6545 & 0.6236 \\
Mini Mono/Sprint & 0.0001 & 0.0004 \\
Mini Mono/Sprint + Slide & $<0.0001$ & $<0.0001$ \\
Mini Mono + Slide/Quick & $<0.0001$ & $<0.0001$ \\
Mini Mono + Slide/Sprint & $<0.0001$ & $<0.0001$ \\
Mini Mono + Slide/Sprint + Slide & 0.0084 & 0.0114 \\
Quick/Sprint & 0.0094 & 0.0289 \\
Quick/Sprint + Slide & $<0.0001$ & $<0.0001$ \\
Sprint/Sprint + Slide & $<0.0001$ &
\end{tabular}

Table 4: Mann-Whitney test for the effect of wire alloy

\begin{tabular}{llr}
\hline $\begin{array}{l}\text { Mann-whitney } \\
\text { test } \mathrm{P}<0.05\end{array}$ & Friction & $\begin{array}{l}\text { NiTi/ } \\
\text { stainless steel }\end{array}$ \\
\hline Damon & Static & 0.6263 \\
& Kinetic & 0.2428 \\
Quick & Static & 0.7251 \\
& Kinetic & 0.3577 \\
Step & Static & 0.739 \\
& Kinetic & 0.938 \\
Mini mono & Static & 0.872 \\
& Kinetic & 0.233 \\
Spint & Static & 0.006 \\
& Kinetic & 0.001 \\
Step + Slide & Static & 0.015 \\
& Kinetic & $<0.0001$ \\
Mini Mono + Slide & Static & 0.001 \\
& Kinetic & $<0.0001$ \\
Sprint + Slide & Static & $<0.0001$ \\
& Kinetic & $<0.0001$ \\
\hline
\end{tabular}

Effect of wire alloy: A significant alloy effect was detected $(\mathrm{P}=0.0001)$ by the Kruskal-Wallis test (Table 4). Post hoc pairwise comparisons showed that NiTi wires produced significant $(\mathrm{P}<0.05)$ higher static and kinetic friction than stainless steel wires when used with Sprint brackets with traditional ligatures and with Mini Mono, Sprint and Step with Slide ligatures. No significant differences were found between $\mathrm{NiTi}$ and stainless steel wires if used in combination with selfligating brackets.

Effect of wire size: Friction increased proportionally with wire section for all the groups tested (Table 5). The Kruskal-Wallis test showed a significant wire section effect $(\mathrm{P}=0.0001)$. Post hoc pairwise comparisons showed significantly lower friction between $0.016 "$ and $0.018 " \mathrm{x} 0.025 "$ and between 0.016 " and 0.019 " $\times 0.025$ " for self-ligating brackets; no statistical difference were found between 0.018 " $\times 0.025$ " and 0.019 " $\times 0.025$ ". With Step brackets 0.016 " produced lower friction than 0.018 " $\mathrm{x} 0.025$ " both in static $(P=0.012)$ and in kinetic $(P=0.009)$. There was high significance $(\mathrm{P}<0.0001)$ between $0.016 "$ and $0.018 " \times 0.025$ " and between $0.016 "$ and 0.019 " $\times 0.025$ " when wires were used in combination with Step and Slide ligatures. Using Sprint brackets, a significant frictional difference was observed between 0.018 " $\times 0.025$ " and 0.019 " $\times 0.025$ " in static $(\mathrm{P}=0.045)$ and kinetic $(\mathrm{P}=0.006)$ friction and between 0.016 " and $0.019 " \times 0.025 "$ in static $(\mathrm{P}=0.042)$. Using Sprint brackets in combinations with Slide ligatures, statistically significant differences were between 0.016" and 0.019 " $\times 0.025$ " wires in static $(\mathrm{P}=0.009)$ and kinetic $(\mathrm{P}<0.0001)$ and between 0.018 ' $\times 0.025$ " and 0.019 " $\times 0.025$ " wires in kinetic $(\mathrm{P}=0.033)$. Using Mini Mono with Slide ligatures we saw significant differences ( $\mathrm{P}=0.021$ ) between 0.016 " and 0.018 " $\times 0.025$ " wires in static and between 0.016 " and 0.019 " $\times 0.025$ " wires $(\mathrm{P}<0.0001)$ both in static and in kinetic.

Table 5: Mann-Whitney test for the effect of wire size

\begin{tabular}{|c|c|c|c|c|}
\hline $\begin{array}{l}\text { Mann-whitney } \\
\text { test } \mathrm{P}<0.05\end{array}$ & Friction & $\begin{array}{l}0.016 " / 0.018 \\
" \times 0.025 "\end{array}$ & $\begin{array}{l}0.016 " / 0.019 \\
" \times 0.025 "\end{array}$ & $\begin{array}{l}0.018 " \times 0.025 \\
" / 0.019 " \times 0.025 "\end{array}$ \\
\hline \multirow[t]{2}{*}{ Damon } & Static & 0.0072 & $<0.0001$ & $<0.0001$ \\
\hline & Kinetic & 0.0168 & 0.0009 & 0.0009 \\
\hline \multirow[t]{2}{*}{ Quick } & Static & 0.0003 & $<0.0001$ & 0.0699 \\
\hline & Kinetic & 0.0003 & $<0.0001$ & 0.3372 \\
\hline \multirow[t]{2}{*}{ Step } & Static & 0.0120 & 0.1230 & 0.7530 \\
\hline & Kinetic & 0.0090 & 0.5010 & 0.2790 \\
\hline \multirow[t]{2}{*}{ Mini mono } & Static & 0.2130 & 1.0000 & 0.2070 \\
\hline & Kinetic & 0.2190 & 1.0000 & 0.2580 \\
\hline \multirow[t]{2}{*}{ Spint } & Static & 0.1170 & 0.5340 & 0.0450 \\
\hline & Kinetic & 0.0960 & 0.0420 & 0.0060 \\
\hline \multirow[t]{2}{*}{ Step + Slide } & Static & $<0.0001$ & $<0.0001$ & 1.0000 \\
\hline & Kinetic & 0.2070 & 0.2070 & 0.1470 \\
\hline \multirow[t]{2}{*}{ Mini Mono + Slide } & Static & 0.0210 & $<0.0001$ & 1.0000 \\
\hline & Kinetic & 0.2670 & $<0.0001$ & 0.4530 \\
\hline \multirow[t]{2}{*}{ Sprint + Slide } & Static & 1.0000 & 0.0090 & 0.1230 \\
\hline & Kinetic & 1.0000 & $<0.0001$ & 0.0330 \\
\hline
\end{tabular}


Current Research in Dentistry 3 (1): 1-6, 2012

Table 6: Mann-Whitney test for the effect of ligature

\begin{tabular}{llr}
\hline Mann-whitney test & & \\
$\mathrm{P}<0.05$ & Friction & Slide/traditional \\
\hline Step & Static & $<0.0001$ \\
& Kinetic & $<0.0001$ \\
Mini mono & Static & $<0.0001$ \\
& Kinetic & $<0.0001$ \\
Spint & Static & $<0.0001$ \\
& Kinetic & $<0.0001$ \\
\hline
\end{tabular}

Effect of ligature: A significant ligature effect was shown $(\mathrm{P}=0.0001)$ by the Kruskal-Wallis test (Table 6). Post hoc pairwise comparisons showed that Slide ligatures produced significant lower frictional forces than traditional elastomeric ligatures both for static and kinetic $(\mathrm{P}<0.0001)$.

\section{DISCUSSION}

Dental materials, that range from polymers to metals, shoud have maximum biocompatibility and show minimal side effects (Atai and Atai, 2007). Moreover orthodontic tooth movement is affected by a combination of biological and mechanical factors. The magnitude of force during orthodontic treatment will result in optimal tissue response and rapid tooth movement. Therefore orthodontic movement should be impressed with low forces (Berger, 2000), thus ensuring treatment efficiency in respect of biologic principles (Thorstenson and Kusy, 2003), oral flora (Koshy et al., 2008) arch forms (Mohammad et al., 2011) and allowing correct jaw movements (Zhuohua et al., 2010). Friction at the bracket archwire interface might prevent the attainment of optimal force levels in the supporting tissues. Therefore, an understanding of forces required to overcome friction is important so that the appropriate magnitude of force can be used to produce optimal biological tooth movement (Tabakman, 2005). To understand and explain the nature of friction between arch wire and bracket, several variables such as bracket material, wire material and alloy and type of ligature should be studied.

Static friction has more importance than kinetic friction in tooth movement: when a tooth slides along an archwire, the tooth movement that occurs is a series of short jumps as archwire and biological resistance strive to upright the root through the alveolar bone, with the static frictional resistance needing to be overcome each time the tooth moves a little (Harradine, 2003).

The present study showed that self-ligating brackets generated significantly lower frictional resistance than conventional stainless steel brackets with conventional ligatures. These findings agree with previous papers that reported that self-ligating brackets produced lower frictional resistance than conventional stainless steel brackets (Berger, 2000; Cacciafesta et al., 2003). Passive self-ligating Damon 3 MX produced statistically less frictional force than interactive selfligating Quick did; this is in agreement with other authors in literature (Henao and Kusy, 2004). An explanation for the reduced friction values is that passive self-ligating cap does no press against the wire and, when the cover is locked, the slot is converted into a tube (Cacciafesta et al., 2003).

Each bracket was tested in combination with three sections wires $(0.016 ", 0.018 " \times 0.025 "$ and 0.019 " $\times 0.025$ "). The higher was the wire size, the higher was the friction produced. This is in agreeing with some previous researches (Cacciafesta et al., 2003; Henao et al., 2004).

In the present investigation passive self-ligating brackets produced lower friction force than interactive self-ligating brackets. This finding is in agreement with previous studies that compared the frictional properties of active and passive self-ligating brackets (Hain et al., 2003; Thorstenson and Kusy, 2003). Interactive selfligating brackets in combination with small wires developed low frictional forces; in combination with higher wires interactive self-ligating showed higher friction values.

Statistically significant differences were found between passive self-ligating brackets Damon 3 MX and interactive self-ligating Quick. This result agrees with previous studies which compared the frictional properties of self-ligating brackets (Hain et al., 2003; Thorstenson and Kusy, 2003).

Statistically significant differences were found between Slide ligatures and traditional elastic ligatures. In this study we used round traditional non lubricated ligatures in modules. Elastomeric ligature presses the wire into the slot and increases the frictional forces need to begin the motion. New Slide ligatures have a design that allowed transforming the slot into a tube where the wire slides easily; for this reason Slide ligatures showed significantly lower friction than traditional elastomeric ligature, in agreement with other Authors (Gandini et al., 2008).

This study also demonstrated that NiTi archwire generated higher friction than SS archwire for all bracketwire combinations. In literature previous studies showed that stainless steel archwires showed higher, lower or equal frictional forces when compared with NiTi archwires (Articolo et al., 2000; Hain et al., 2003; Cacciafesta et al., 2003; Chimenti et al., 2008; Wichelhaus et al., 2005). This variability of the results is probably due to the different materials tested in the studies. 


\section{CONCLUSION}

The result of the present study demonstrates that passive self-ligating brackets and conventional brackets with Slide ligatures generated significantly lower static and kinetic frictional forces than both interactive selfligating and conventional brackets with traditional ligatures. NiTi archwires had higher frictional forces than stainless steel archwires; all brackets showed higher static and kinetic frictional forces as the wire size increased.

\section{ACKNOWLEDGEMENT}

We thank Ormco, Leone and Forestadent for the materials provided.

\section{REFERENCES}

Articolo, L.C., K. Kusy, C.R. Saunders and P.P. Kusy, 2000. Influence of ceramic and stainless steel brackets on the notching of archwires during clinical treatment. Eur. J. Orthod., 22: 409-425. DOI: $10.1093 /$ ejo/22.4.409

Atai, Z and M., Atai, 2007. Side effects and complications of dental materials on oral cavity. Am. J. Applied Sci., 4: 946-949. DOI: 10.3844/ajassp.2007.946.949

Berger, J., 2000. Self-ligation in the year. J. Clin. Orthod., 34: 74-81.

Cacciafesta, V., M.F. Sfondrini, A. Ricciardi, A. Scribante and C., Klersy et al., 2003. Evaluation of friction of stainless steel and esthetic self-ligating brackets in various bracket-archwire combinations. Am. J. Orthod. Dentofacial Orthop., 124: 395-402. DOI: 10.1016/S0889-5406(03)00504-3

Chimenti, C., L. Franchi, M.G. Di Giuseppe and M., Lucci, 2008. Friction of orthodontic elastomeric ligatures with different dimensions. Angle Orthod., 75: 421-425.

Gandini, P., L. Orsi, C., Bertoncini, S., Massironi and L., Franchi, 2008. In vitro frictional forces generated by three different ligation methods. Angle Orthod 78: 917-921. DOI: 10.2319/090607420.1

Griffiths, H.S., M. Sheriff and A.J. Ireland, 2005. Resistance to sliding with 3 types of elastomeric modules. Am. J. Orthod. Dentofacial Orthop., 127: 670-675. DOI: 10.1016/j.ajodo.2004.01.025

Hain, M., A. Dhopatkar and P. Rock, 2003. The effect of ligation method on friction in sliding mechanics. Am. J. Orthod Dentofacial Orthop., 123: 416-422. DOI: $10.1067 / \bmod .2003 .14$
Harradine, N.W.T., 2003. Self-ligating brackets: Where are we now? J. Orthod., 30: 262-273. DOI: 10.1093/ortho/30.3.262

Henao, S.P. and R.P. Kusy, 2004. Frictional evaluations of dental typodont models using four self-ligating designs and a conventional design. Angle Orthod., 75: 75-85.

Kusy, R.P. and J.Q. Whitley, 2001. Frictional resistances of metal-lined ceramic brackets versus conventional stainless steel brackets and development of 3-D friction maps. Angle Orthod. 71: 364-74.

Koshy P., W.Y., Teoh, S., Muniandy and H., Yaakob, 2008. Identification of major cultivable aerobic bacteria in the oral cavity of Malaysian subjects. Am. J. Biochem. Biotechnol., 4: 367-370. DOI: 10.3844/ajbbsp.2008.367.370

Mohammad, H.A., M.I.A., Hassan and S.F., Hussain, 2011. Dental arch dimension of Malay ethnic group. Am. J. Applied Sci., 8: 1061-1066. DOI: 10.3844/ajassp.2011.1061.1066.

Northrup, R.G., D.W. Berzins, T.G. Bradley and W. Schuckit, 2007. Shear bond strength comparison between two orthodontic adhesives and selfligating and conventional brackets. Angle Orthod., 77: 701-706. DOI: 10.2319/022406-79

Sfondrini, M.F., D. Fraticelli, B. Balconi, A. Scribante and P. Gandini, 2010. Effect of saliva moistening on shear bond strength of self ligating orthodontic brackets. Curr. Res. Dent., 1: 23-28.

Sfondrini, M.F., S. Gatti and A. Scribante, 2011. Shear bond strength of self-ligating brackets. Eur. J. Orthod., 33: 71-74. DOI: 10.1093/ejo/cjq041

Tabakman, V., 2005. Evaluation of frictional resistance in resin self-ligating bracket, stainless steel selfligating bracket and ceramic brackets. Am. J. Orthod Dentofacial Orthop., 128: 263-264. DOI: 10.1016/j.ajodo.2005.05.007

Thorstenson, G.A. and R.P. Kusy, 2003. Effects of ligation type and method on the resistance to sliding of novel orthodontic brackets with second-order angulation in the dry and wet states. Angle Orthod., 73: 418-430.

Wichelhaus, A., M. Geserick, R. Hibst and F.G. Sander, 2005. The effect of surface treatment and clinical use on friction in NiTi orthodontic wires. Dent Mater., 21: 938-945. $\quad$ DOI: 10.1016/j.dental.2004.11.011

Zhuohua, L., M., Zecca, S., Sessa, H., Ishii and A., Takanishi, 2010. Development of an ultraminiaturized inertial measurement unit for jaw movement analysis during free chewing. J. Comput. Sci., 6: 896-903. DOI: 10.3844/jcssp.2010.896.903 